\title{
Predicting Daily Pore Water Pressure in Embankment Dam Using Machine Learning Models and Hydrostatic Seasonal Time Approach
}

\section{Ali El Bilali ( $\square$ ali1gpee@gmail.com )}

Hassan II University: Universite Hassan II Casablanca https://orcid.org/0000-0002-5744-3086

\section{Mohammed Moukhliss}

Hassan II Mohammedia University Faculty of Science and Technology Mohammedia: Universite Hassan II Casablanca Faculte des Sciences Techniques Mohammedia

\section{Abdeslam Taleb}

Hassan II Mohammedia University Faculty of Science and Technology Mohammedia: Universite Hassan II Casablanca Faculte des Sciences Techniques Mohammedia

\section{Ayoub Nafii}

Hassan II Mohammedia University Faculty of Science and Technology Mohammedia: Universite Hassan II Casablanca Faculte des Sciences Techniques Mohammedia

\section{Bahija Alabjah}

Hassan II Mohammedia University Faculty of Science and Technology Mohammedia: Universite Hassan

II Casablanca Faculte des Sciences Techniques Mohammedia

\section{Youssef Brouzyine}

Mohammed VI Polytechnic University: Universite Mohammed VI Polytechnique

\section{Nouhaila Mazigh}

Hassan II Mohammedia University Faculty of Science and Technology Mohammedia: Universite Hassan II Casablanca Faculte des Sciences Techniques Mohammedia

\section{Khalid Teznine}

River basin agency of Bouregreg

\section{Madark Mhamed}

River basin agency of bouregreg

\section{Research Article}

Keywords: Dam safety, machine learning models, Hydrostatic Seasonal Time model, Heimer dam, pore water pressure

Posted Date: November 2nd, 2021

DOI: https://doi.org/10.21203/rs.3.rs-947164/v1 
License: (c) (i) This work is licensed under a Creative Commons Attribution 4.0 International License. Read Full License 
1 Predicting daily pore water pressure in embankment dam using machine learning models and Hydrostatic Seasonal Time approach

3

4 Ali EL Bilali ${ }^{1,2 *}$, Moukhliss, Mohammed ${ }^{1}$, Abdeslam Taleb $^{1}$, Ayoub Nafii $^{1,2}$, Bahija Alabjah ${ }^{3}$, Youssef Brouzyine $^{4}$, Nouhaila Mazigh ${ }^{1}$, Khalid Teznine $^{2}$, Madark Mhamed $^{2}$

6

7 1: Hassan II university of Casablanca, Faculty of Sciences and Techniques of Mohammedia, Morocco.

8 2: River Basin Agency of Bouregreg and Chaouia, Morocco

9 3: Hassan II university of Casablanca, Faculty of Sciences Ain Chock, Lab. of Geosciences applied to 10 Engineering Development (GAIA), Casablanca, Morocco 


\title{
Predicting daily pore water pressure in embankment dam using machine learning models and Hydrostatic Seasonal Time approach
}

\begin{abstract}
Prediction-based approaches are valuable in assessing dam safeties, as they allow comparing the actual measurements with the projected values to detect anomalies early. For two decades, machine learning (ML) algorithms have been developed and improved to help in accurately predicting the dam behaviors. However, the generalization ability (GA) of these models is not analyzed enough in dam engineering. In this study, the Multiple Linear Regression (MLR), Artificial Neural Network (ANN), Support Vector Regression (SVR), and Adaptive Boosting (AdaBoost) models with nonlinear autoregressive exogenous inputs (NARX) are evaluated and compared with the conventional Hydrostatic Seasonal Time (HST) model for predicting the daily pore water pressure in an embankment Dam. Moreover, we proposed a classification method of the model into four categories 'Perfect',, 'Excellent',, 'Good', and 'Poor' according to the GA. Results showed that, except for the AdaBoost, the other ML models outperformed the traditional statistical approach (HST) in terms of prediction accuracy as well as the GA. Overall; the study results provide new insights in enhancing the monitoring processes and dam safeties by detecting the anomalies early through the measurements and the selection of the best fitted-models.
\end{abstract}

Keywords: Dam safety, machine learning models, Hydrostatic Seasonal Time model, Heimer dam, pore water pressure.

\section{Introduction}

Dams are important hydraulic infrastructures in water resources planning and management, as they play an important role in supplying water for drinking and irrigation purposes, energy production, recreation, and flood control. However, these infrastructures present potential risks related to their failure, which can generate a flood disaster downstream losing life and economic damage (El Bilali et al., 2021; Talukdar and Dey, 2019). Consequently, managing dams requires integrating double issues such as dam safety and effective operations to manage the water resources. Indeed, monitoring the safety of these infrastructures through the measurement of several indicators is a crucial task. Historically, ICOLD reported that an important percentage of the failed dams did not have a monitoring system of safety (Johansson, 1997). Therefore, analyzing the structure behaviors under different conditions, and checking the measurements with the predicted data are considered essential tasks in dam monitoring.

To predict and interpret the dam behaviors, several mathematical models and approaches have been developed and investigated over time. The modeling of the dam behaviors includes two approaches namely, mechanistic-based models and statistical-based models. The mechanistic based-models base on the explanation of the physical processes involved in the dam behavior. The mass conservation, heat transfer, and Darcy laws are the main components of the mechanistic models of the dam behaviors (Bear, 2013; Guo et al., 2018; Qin et al., 2017; 
Zewdu, 2020). Indeed, the construction process of these models is difficult, as it requires several physical parameters and input variables, which are generally laborious to get. Meanwhile, this approach is valuable to evaluate the stability of the structures during their conception and building rather than management and interpretation of the data measurements related to safety monitoring. Additionally, in addition to the prediction accuracy, simple and faster computations are required in dam safety monitoring thereby the engineers can detect the anomaly cheaply. Hence, the statistical approach is suggested for such purposes.

Hydrostatic season time (HST) is the first model developed to predict and interpret dam behaviors(Ferry and Willm, 1958; Willm and Beaujoint, 1967). Indeed, this model is a statistical-based approach broadly used in engineering practices of dam safety monitoring (Gamse et al., 2018; Li et al., 2015; Salazar et al., 2017). This approach bases on the hydrostatic pressure of the water reservoir, seasonal fluctuation, and time or irreversible factors. Compared to the mechanical models, the statistical-based models are developed based on regression methods to construct different correlations ship between affective variables and behavior variables. For instance, multiple-linear regression (MLR) is one of the commonly applied traditional regression methods to determine the HST coefficients. However, this method can be defected due to the multi-collinearity among independent variables and nearlinear dependence of repressors, which can significantly impact the variances for the least square estimators of the regression coefficients and, therefore, the prediction accuracy of the models. To overcome this limitation, the step multi regression (SMR), the partial least-square regression (LSR), truncated singular value decomposition (TSVD), and principal component regression (PCR) methods have been proposed and investigated (Rosipal and Trejo, 2001; Xu and Deng, 2011).

During the last two decades, the application of machine learning (ML) algorithms has increased in different fields. The ML models have the capability to fit nonlinear and high complex systems without explanation of the mechanism involved in these systems. In dam safety modeling, Artificial Neural Network (ANN) and support vector regression (SVR) are largely applied in modeling the safety of the concrete dams (Belmokre et al., 2019; Chen et al., 2021; de Granrut et al., 2019; Fisher et al., 2017; Kang et al., 2019; Mata, 2011). Interestingly, Salazard et al. (Salazar et al., 2015) applied ANN, SVR, and tree-based models to predict the displacement and leakage of the arch dam, in Spain and showed good prediction accuracy of the ML models compared to the HST one. Additionally, extreme learning machine algorithms showed being powerful tools in modeling of dam behaviors. For instance, Chen et al., (2020) applied an adaptive kernel extreme learning machine to predict the leakage flow of concrete face rock-fill dam and the case study revealed satisfactory accuracy. Kang et al., (2017) used, also, ELM models to predict the displacement of concrete dam and showed good accuracy of this approach. Besides, support vector machine (SVM) and naive Bayesian classifier have been applied in classification tasks to develop a simplified reliability analysis for gravity dams (Hariri-Ardebili and Pourkamali-Anaraki, 2018).

Nevertheless, the systematic review showed that the ML-based modeling studies focus more on concrete-based construction dam structure behaviors than embankment and earth dams. Moreover, few studies focused on seepage modeling for the embankment dams (Rehamnia et 

al., 2021; Tang et al., 2020; Wang et al., 2018; Xiang et al., 2017). Indeed, the estimation of the seepage can help to evaluate technical precautions anti-seepage to avoid the dam failure, particularly for high water levels (Al-Fares, 2011; Sica et al., 2019). However, for large dams, the spatial detection of the seepage anomalies is not easy and needs cost methods such as electrical investigation and self-potential methods(A1-Saigh et al., 1994; Panthulu et al., 2001). Interestingly, evaluating the dam safety early could be efficient tool to either avoid dam failure or mitigate the flood risk by evacuation of the population at risk (El Bilali et al., 2021). However, measurement of the pore water pressure is one of the indicators used in dam surveillances, particularly for earth and embankment dams. The distribution of this indicator throughout the structure describes the slop stability of the embankment and earth dams either for the building phases or during the safety monitoring (Desideri et al., 2013; Pagano et al., 2010). Also, measurements of the pore water pressure can examine the dam seepage. Interestingly, detecting anomalies in seepage measurements, through either significant variation in flow or watercolor, needs interpretation of the pore water pressure measurements to identify the localization of the detected anomalies along the dam. Therefore, the predictionbased approach is suggested to enhance the pore water pressure interpretation. Additionally, the high frequency of the measurements provides a reliable trend of dam behaviors in early detecting the anomalies and managing the failure risk. Consequently, the modeling of daily water pore pressure could be valuable for prediction purposes under different conditions to interpret the measurements in the monitoring of the embankment dam safety. For this purpose, ML-based models with exogenous input variables may be powerful tools for modeling the daily pore water pressure.

Besides, the literature review showed that the GA is not analyzed enough for selecting the best models in predicting the dam behaviors, except for summary analysis and general discussion based on the prediction accuracy (Salazar et al., 2017). The statistical model generalization ability (GA) is a crucial metric, as it measures the reliability and utility of the models over time. The analysis of the GA aims to evaluate whether the models can predict the target for unseen datasets during their training (calibration) without significant variation of the performances over time. Consequently, there is a need to introduce and use the GA as a metric for selecting the appropriate statistical-based models for predicting the dam behaviors.

This work aims at developing and comparing four ML models and the HST model to predict the daily pore pressure at 11 Piezometers in an embankment dam in Morocco. To that end, Adaptive boosting (AdaBoost), SVR, ANN, and Multiple linear regression (MLR) models are trained and validated using exogenous input variables to overcome the instantaneous response assumption of the HST model. The performances of these models are compared to those of the HST model. Besides, all models are ranked against their GA. Furthermore, the uncertainty analysis was carried out to determine the confidence interval (CI) of the models for practical implication purposes.

\section{Material and methods}

\subsection{HST-based approach}


In general, a dam structure in normal operation is influenced by hydrostatic load due to the water level, seasonal, and time factors. Accordingly, increasing in water level increases the pore pressure in the embankment dam, so impacting the slope stability and the seepage. Meanwhile, the seasonal factors can include either the thermal effects on the concrete-based construction dam behaviors or the rainfall effects on the pore water pressure in embankment and earth dams. However, the pore water pressure can described by the following equation (Ferry and Willm, 1958):

$$
y=a_{0}+y_{h}+y_{\theta}+y_{s}+e
$$

Where y is the measured pore pressure through the installed sensors, $y_{h}$ is the hydrostatic load sub-model, $y_{\theta}$ is the time effect sub-model (irreversible term), $y_{s}$ is the seasonal sub-model, and $e$ is the model error.

The hydrostatic load sub-model $h_{h}(h)$ is often modeled by polynomial function depending on the reservoir water level $(h)$.

$$
y_{h}(h)=\sum_{i=1}^{n} a_{i}\left(\frac{R_{n}-h}{R_{n}-R_{v}}\right)^{i}
$$

Where $R_{n}$ is the normal water level, $R_{v}$ is the minimum water level, and $a_{i}(i=1,2 \ldots n)$ called water level regressors corresponding to the $i^{\text {th }}$ degree. Generally, the degree of this polynomial function is taken $n=4$ (Bonelli and Félix, 2001; Simon et al., 2013).

The behavior dam over time has been modeled by several researchers and the general form of the equation is given by equation (3) (Carrere and Noret-Duchêne, 2001; Chouinard and Roy, 2006; Mata, 2011; Simon et al., 2013).

$$
y_{\theta}=a_{n+1} e^{-\frac{t}{\tau}}+a_{n+2} \cdot t+a_{n+3} t^{2}+a_{n+4} t^{3}+a_{n+5} t^{4}
$$

Meanwhile, the seasonal effects on the dam behaviors can be described by the trigonometric function as follow:

$y_{s}=a_{n+6} \sin \left(\frac{2 \pi}{365} t\right)+a_{n+7} \cos \left(\frac{2 \pi}{365} t\right)+a_{n+8} \sin \left(2 \frac{2 \pi}{365} t\right)+a_{n+9} \cos \left(2 \frac{2 \pi}{365} t\right)$

With $a_{n+i}$ are the model regressors while $t$ is the time (day) starting from the initial observation of monitoring process.

In this study, we enabled and disabled all the sub-model regressors with the aim to select the best fitted models for predicting the pore water pressure. Besides, both these regressors and the solver algorithms were selected basing on the trial-error procedure. To that end, DamBASE software was set up and used to calibrate and validate the HST models in predicting the pore pressure. It was selected; as it is capable determine the regressors of HST model using several algorithms such as ridge, least square regression, PCR, and Prais-winsten where the user is able to adjust easily the repressor models (SFOE, 2015). This software is commissioned by the Swiss Federal Office of Energy (SFOE) based on R environment and is freely available. 


\subsection{Overview on the used ML models}

Machine learning models are classified into two sub-sections: classification and regression models. In this study, we adopted the regression models, such as the multiple linear regression (MLR), support vector regression (SVR), artificial neural network (ANN), and adaptive boosting (AdaBoost) models. The support vector regression (SVR) is a discriminative method that can applied for regression and classification problems and has been introduced by Vapnik, (1995). This approach is based on a hyper-plane to minimize the error and the kernel function such as radial basis function (RBF) (Ghosh, 2010), Sigmoid, linear kernel, and polynomial function. Adaptive boosting (AdaBoost) is a tree-based ensemble ML model (Freund and Schapire, 1996; Schapire, 1999). It is based on the training of several weak learners where the prediction for new datasets is carried out by combining weighted of these models. ANN models are constructed by three layers such as input layer, hidden layers, and output layer. These layers are interconnected through the neurons that are characterized by weight and bias. The weighted and summed variables (with the bias of the layer) are transformed from the layer $\mathrm{i}^{\text {th }}$ to the $(\mathrm{i}+1)^{\text {th }}$ one through a transfer function $(f)$ (Dawson and Wilby, 1998). The training process is iteratively repeated by changing the weights and the biases of the layers until good preliminary performance. However, further details on the MLbased models can be found in (Aggarwal, 2015; Bishop, 2006; Bonaccorso, 2018; Freund and Schapire, 1997; Hastie et al., 2009; Kubat, 2017).

\subsection{Methodology}

\subsubsection{Input-output NARX method}

Considering $\mathrm{N}$ of measurement datasets related to the system $(S)$ subject of the modeling study using based-ML algorithms, $S=\left\{\left(X_{i}\right.\right.$, Dam safety, machine learning models, Hydrostatic Seasonal Time model, Heimer dam, pore water pressure. $\left.\left.y_{i}\right), i=1,2, \ldots N\right\}$ where $X_{i}=\left[x_{i, 1}, x_{i, 2}\right.$, $\left.x_{i, 3} \ldots x_{i, p}\right]^{T}$ is the input matrixes ( $p$ is the input numbers), $y_{i}=\left[y_{i, 1}, y_{i, 2}, y_{i, 3} \ldots y_{i, q}\right]^{T}$ is the output vector and, $i$ is the time instant. Given that the embankment dam behaviors in responding to the reservoir water level are delayed by the hydraulic conductivity, using NARX-based modeling is suggested to describe and model the non-linear dam behaviors (Beskhyroun et al., 2011; Ranković et al., 2014). Therefore, the NARX-based machine learning (ML) models for predicting the pore water pressure in embankment dam have NARX input-output variables as follow:

$$
y_{i}=M L f_{m}(\varphi(i), \theta)
$$

Where $\varphi(i)=\left(x_{i}, x_{i-1}, x_{i-2}, \ldots, x_{i-l x}, y_{i-1}, y_{i-2}, \ldots, y_{i-l y}\right)$ the regression vector, $\theta$ is the parameter vector, $M L f_{m}$ is the unknown machine learning model function; $l x$ and $l y$ denote the lag numbers of the input $\mathrm{x}$ and output $\mathrm{y}$, respectively. Therefore, the final input matrixes $X_{i}^{T}$ and the output vector $y_{i}^{T}$ for training of the machine learning models are as follow:

$$
\left\{\begin{array}{c}
X^{T}=\left[x_{i}, x_{i-2}, \ldots, x_{i-l x}, y_{i-1}, y_{i-2}, \ldots, y_{i-l y}\right] \\
y^{T}=y_{i} \\
\max (l y, l x)<i \leq N
\end{array}\right.
$$


The unknown function $M L f_{m}$ of ML models includes the hyper-parameter, loss functions, and model structures depending on the model. For instance, Number of the hidden layers and function transfer for ANN model, kernel function, and penalty parameter (C) for SVR model. However, the $M L f_{m}$ and the lag numbers are identified during the tuning process using trialerror procedures.

\subsubsection{Evaluation method of the models}

The applied model performances are evaluated using two statistical criteria such as coefficient of determination $\mathrm{R}^{2}$ and root mean square error (RMSE). $\mathrm{R}^{2}$ value of 1 demonstrates perfect correlation between the observed and predicted values but do not imply good accuracy, particularly for modeling the dam behaviors where the multi-colinearity is considered as a great challenge. In contrast, lower value of the $\mathrm{R}^{2}$ indicates poor fitted model. Meanwhile, the lower RMSE value compared to the magnitude of the model outputs shows good fitted model. However, in statistical-based modeling approach, the generalization ability (GA) of the model is crucial metric in evaluating such model for prediction purposes to interpret the measurements. Interestingly, the good prediction accuracy of a model dot not implies it's utility if it is not generalizable and stable, as it can be deteriorated for new dataset. It is noted that a significant decrease in the model performances during the validation process explains that the model likely will be deteriorated over time. In constraint, the significant increase in the prediction accuracy shows that the base line model is not well trained and is fragile. However, Yoon et al (Yoon et al., 2011) defined the GA by the equation (7) and applied by (C. Chen et al., 2020; El Bilali et al., 2020) in comparing ML models.

$$
G A=\frac{R M S E \text { during the validation }}{R M S E \text { during the training }}
$$

GA value higher than unity indicates the model is over-fitted; while less than unity the model is under-trained. However, and to evaluate the model in this study, we proposed the classification of the developed models according four categories, namely Prefect, Excellent, Good, and Poor in term of GA as following:

- $\mathrm{GA}=1$, model is 'Perfect'".

- $0.75 \leq \mathrm{GA}<1$ or $1<\mathrm{GA} \leq 1.35$, the model is ''Excellent'".

- $1.35<\mathrm{GA} \leq 2$ or $0.5 \leq \mathrm{GA}<0.75$, the model is ' Good'.

- GA $>2$ or $\mathrm{GA}<0.5$, the model is "Poor" and considered unsuitable for prediction purposes.

\subsection{Studied dam}

\subsubsection{Dam description}

The case study concerns the embankment dam of Heimer in the north west of Morocco with coordinates $\left(-7.34587^{\circ}, 33.10523^{\circ}\right)$ according to the World Geodetic System (WGS84). It was commissioned in 2009 on the Heimer River to control a watershed of the surface area of about $188 \mathrm{Km}^{2}$ to mitigate the flood risk of the downstream plain. The length of the dam crest is 
$740 \mathrm{~m}$; the maximum height is $37.5 \mathrm{~m}$, the elevation of the normal reservoir level is $446.5 \mathrm{~m}$ (meter sea level), the capacities of the reservoir are $14 \mathrm{Mm}^{3}$ and $17.7 \mathrm{Mm}^{3}$ at the normal level and the maximum of the headwater level $(448.7 \mathrm{~m})$, respectively. This dam is monitored by the topographic survey for one time by year and the measurement of the pore water pressure through VW piezometers at different localizations. However, Figure 1a presents a satellite image of the dam and the Piezometer localizations while Figure $1 \mathrm{~b}$ illustrates the elevations of the piezometers used in this study. In this study, we focus on the modeling of the pore water pressure measured at the dam foundation by $11 \mathrm{VW}$ Piezometers.
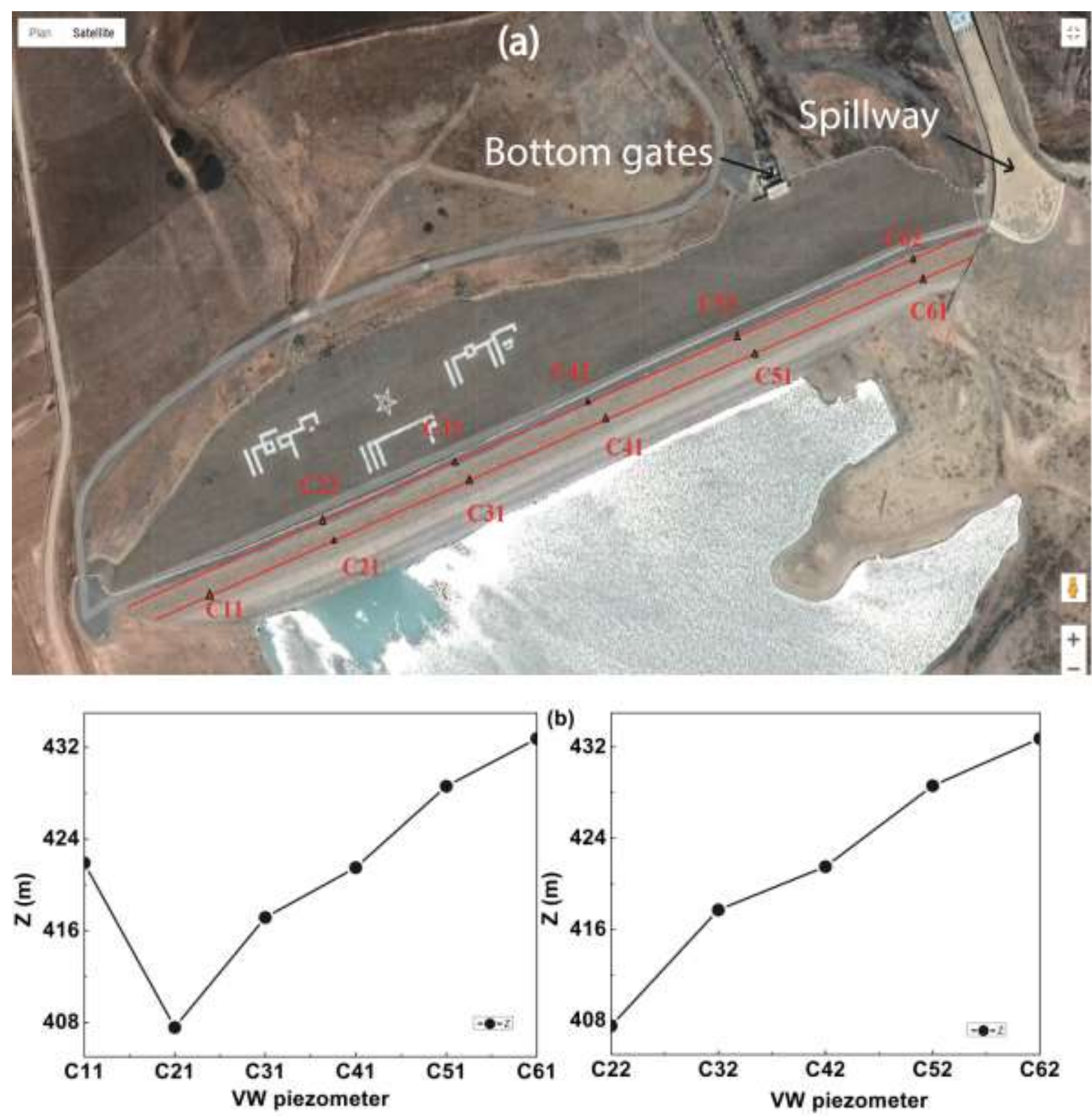

Figure 1: Description of the studied dam (a) and the Piezometer elevations (b).

\subsubsection{Measurement principle and data collection}


The pore water pressure in the studied dam is measured by the VW piezometers. This instrument consists of a magnetic tensioned wire one of its ends is attached to the flexible diaphragm and the other is fixed to the sensor body. When the diaphragm deflects (under pore water pressure variation) the resonant frequency of the tensioned wire changes and, therefore, its measurement can be calibrated against the pore water pressure in the dam. Around the tensioned wire a magnetic coil, which when pulsed by a vibrating readout (Datalogger interface), excites the wire and measures the resultant resonant frequency of vibration. In this study, the measurement is carried out for each hour and the data is stored in Datalogger. However, in this modeling study, we used the daily pore water pressure measured by $11 \mathrm{VW}$ Piezometers installed in the dam foundation (Ci) (Figure 1) and reservoir water level recorded from Jun 1, 2010, to Dec 31, 2020. Table 1 presents the statistical characteristics such as minimum (min), maximum ( $\max$ ), mean, and standard deviation (SD) values of the daily pore water pressure (average of the hourly values) and the water level (h).

Table 1: Summary of datasets daily water level (h) and daily pore pressure at the used Piezometers (Ci).

\begin{tabular}{ccccccccccccc}
\hline \hline & $\mathrm{h}(\mathrm{m})$ & $\mathrm{C} 11$ & $\mathrm{C} 21$ & $\mathrm{C} 22$ & $\mathrm{C} 31$ & $\mathrm{C} 32$ & $\mathrm{C} 41$ & $\mathrm{C} 42$ & $\mathrm{C} 51$ & $\mathrm{C} 52$ & $\mathrm{C} 61$ & $\mathrm{C} 62$ \\
\hline \hline $\min$ & 432.03 & 422.85 & 413.55 & 413.04 & 413.41 & 405.43 & 421.33 & 417.53 & 423.90 & 425.57 & 431.83 & 430.46 \\
$\max$ & 443.34 & 438.06 & 429.60 & 421.57 & 434.33 & 420.38 & 432.17 & 421.58 & 432.74 & 431.35 & 437.02 & 434.06 \\
$\operatorname{mean}$ & 434.16 & 426.09 & 416.61 & 415.29 & 416.23 & 406.74 & 423.21 & 418.81 & 425.26 & 427.16 & 432.63 & 431.13 \\
$\mathrm{SD}$ & 1.92 & 2.71 & 3.06 & 1.70 & 3.72 & 2.74 & 1.93 & 0.81 & 1.73 & 1.22 & 0.88 & 0.65 \\
\hline \hline
\end{tabular}

\section{Results}

\subsection{HST evaluation}

Table 2 presents selected regressors of the HST model in predicting the pore pressure at 11 VW Piezometers installed in the embankment dam (Heimer dam). This table shows that some regressors were disabled (NA) to have good prediction accuracy of the pore water pressure at all Piezometers. Comparing these regressors shows that they differ from a sub-model to another and from one piezometer to another. This may be due to that the Piezometers have not been installed in the same elevations. Also, it can be seen that the regressor values related to the seasonal sub-model $y_{s}$ are small and several of them were disabled compared to those of the other sub-models. Such results demonstrate that the irreversible effects and hydraulic loads are more important than the seasonal effects. Indeed, the thermal effects can be neglected in the modeling of pore water pressure variations in embankment dams, but it is considered in this study to incorporate the rainfall factors. 


\begin{tabular}{|c|c|c|c|c|c|c|c|c|c|c|c|c|}
\hline $\begin{array}{c}\text { Sub- } \\
\text { models }\end{array}$ & Regressor & $\mathrm{C} 11$ & $\mathrm{C} 21$ & $\mathrm{C} 22$ & C31 & C32 & $\mathrm{C} 41$ & $\mathrm{C} 42$ & C51 & C52 & C61 & C62 \\
\hline Intercept & $\mathrm{a} 0$ & 468.227 & 404.157 & 419.895 & 528.050 & 494.619 & 433.633 & 420.438 & 430.551 & 534.181 & 489.996 & 458.306 \\
\hline \multirow{4}{*}{$y_{h}$} & a1 & 0.8902 & 0.5203 & 0.3331 & 0.5157 & 0.0683 & 0.4892 & 0.0158 & -0.0141 & 0.0255 & -0.0029 & -0.0046 \\
\hline & $\mathrm{a} 2$ & 0.0266 & 0.0092 & 0.0049 & 0.0040 & -0.0710 & 0.0137 & 0.0125 & 0.0336 & -0.0077 & 0.0249 & 0.0041 \\
\hline & a3 & -0.0064 & 0.0031 & -0.0062 & -0.0045 & 0.0001 & -0.0041 & NA & NA & -0.0027 & 0.0139 & 0.0088 \\
\hline & $\mathrm{a} 4$ & 0.0005 & -0.0005 & 0.0004 & 0.0005 & 0.0004 & 0.0002 & NA & NA & 0.0006 & -0.0012 & -0.0006 \\
\hline \multirow{5}{*}{$y_{\theta}$} & a5 & -38.6609 & 21.0625 & NA & -98.6594 & -71.8846 & -5.5212 & NA & NA & -104.258 & -57.4906 & -26.8977 \\
\hline & a6 & -15.2793 & 6.9120 & -1.4649 & -44.5382 & -39.1896 & -2.9747 & 0.2032 & -0.7077 & -44.4231 & -23.6865 & -8.3690 \\
\hline & a7 & 2.2507 & -1.0815 & 0.3493 & 7.0542 & 7.1083 & 0.3030 & -0.0791 & NA & 7.4811 & 3.9438 & 0.8363 \\
\hline & $\mathrm{a} 8$ & -0.1551 & 0.0501 & -0.0433 & -0.5166 & -0.6036 & -0.0116 & 0.0034 & NA & -0.5823 & -0.3044 & -0.0207 \\
\hline & a9 & 0.0040 & NA & 0.0017 & 0.0144 & 0.0197 & NA & NA & NA & 0.0170 & 0.0089 & -0.0007 \\
\hline \multirow{4}{*}{$y_{s}$} & a10 & NA & 0.0217 & NA & 0.0949 & -0.0997 & NA & 0.0632 & 0.1634 & NA & 0.0060 & -0.0181 \\
\hline & a11 & -0.0028 & NA & NA & -0.0558 & NA & NA & NA & NA & 0.0005 & NA & -0.0181 \\
\hline & a12 & NA & 0.0002 & NA & 0.0354 & -0.0022 & NA & 0.0256 & 0.0630 & NA & 0.0017 & 0.0037 \\
\hline & a13 & NA & NA & NA & NA & NA & 0.0195 & 0.0237 & NA & 0.0226 & 0.0025 & NA \\
\hline
\end{tabular}

Table 3 presents the performances of the HST model during the training and validation processes and the selected algorithms for different Piezometers. Indeed, during the selection phase, it was observed that there are small discrepancies in the prediction accuracy from an algorithm to another. Regarding the accuracy prediction, it is observed all models have good performances during the training phase with $\mathrm{R}^{2}$ of about 0.99 and lower RMSE (ranging from 0.011 to $0.238 \mathrm{~m}$ ). However, during the validation phase, the HST model performances decreased compared to those obtained during the training phase, particularly for the Piezometers C21, C32, C51, C52, and C62 with RMSEs, 0.417, 0.614, 0.517, 0.396, and $0.235 \mathrm{~m}\left(\mathrm{R}^{2}=0.335\right)$, respectively. Meanwhile, for the other Piezometers, the HST model presented good accuracy in reproducing the pore pressure with RMSEs, 0.093, 0.084, 0.113, 0.092, 0.127, $0.045 \mathrm{~m}$ for C11, C22, C31, C41, C42, and C61 Piezometers, sequentially.

Besides, the generalization ability (GA), as defined previously of the HST model in reproducing the pore pressure, was evaluated and presented in Table 3. It is observed that the HST model is more generalizable with GA $0.861,0.967$, and 1.210, and 1.08 for C11, C22, C31, and C41 piezometers, respectively. Such results demonstrate that these models predict well the pore water pressure for new input datasets. In contrast, for the other Piezometers, the models have "'Poor" GA with values up to 6 , which indicate that the models predict the pore pressure with errors higher than those occurred during the training phase with GA times and, therefore, are more sensitive to the new input variables. On the other hand, it is observed that some failed models have good $\mathrm{R}^{2}$ in predicting the pore water pressure but they have significant RMSEs and GA, particularly for the C32 $\left(\mathrm{R}^{2}=0.858\right), \mathrm{C} 51\left(\mathrm{R}^{2}=0.923\right)$, and C52 $\left(\mathrm{R}^{2}=0.873\right)$ Piezometers. Such results demonstrate that the HST failed to resolve the multicollinearity problem with the selected algorithms, as it was observed that there is a good trend 
between the observed and predicted values but there is a significant discrepancy between the

329 observed and simulated values in terms of the magnitude of pore water pressure.

Table3: Performances and GA of the HST models

\begin{tabular}{|c|c|c|c|c|c|c|}
\hline Piezometers & Step & $\begin{array}{c}\text { Selected } \\
\text { algorithm }\end{array}$ & $\mathrm{R}^{2}$ & RMSE (m) & & \\
\hline \multirow{2}{*}{ C11 } & Training & \multirow{2}{*}{ Least square } & 0.998 & 0.108 & \multirow{2}{*}{0.861} & \multirow{2}{*}{ Excellent } \\
\hline & Validation & & 0.976 & 0.093 & & \\
\hline \multirow{2}{*}{$\mathrm{C} 21$} & Training & \multirow{2}{*}{ Least square } & "0.998 & 0.068 & \multirow{2}{*}{6.156} & \multirow{2}{*}{ Poor } \\
\hline & Validation & & 0.732 & 0.417 & & \\
\hline \multirow{2}{*}{$\mathrm{C} 22$} & Training & \multirow{2}{*}{ Ridge } & 0.997 & 0.087 & \multirow{2}{*}{0.967} & \multirow{2}{*}{ Excellent } \\
\hline & Validation & & 0.974 & 0.084 & & \\
\hline \multirow{2}{*}{ C31 } & Training & \multirow{2}{*}{ PCR } & 0.999 & 0.094 & \multirow{2}{*}{1.210} & \multirow[t]{2}{*}{ Excellent } \\
\hline & Validation & & 0.951 & 0.113 & & \\
\hline \multirow{2}{*}{ C32 } & Training & \multirow{2}{*}{ Least square } & 0.999 & 0.105 & \multirow{2}{*}{5.873} & \multirow{2}{*}{ Poor } \\
\hline & Validation & & 0.858 & 0.614 & & \\
\hline \multirow{2}{*}{$\mathrm{C} 41$} & Training & \multirow{2}{*}{ Least square } & 0.998 & 0.085 & \multirow{2}{*}{1.080} & \multirow{2}{*}{ Excellent } \\
\hline & Validation & & 0.936 & 0.092 & & \\
\hline \multirow{2}{*}{$\mathrm{C} 42$} & Training & \multirow{2}{*}{ Prais-winsten } & 0.997 & 0.041 & \multirow{2}{*}{3.073} & \multirow{2}{*}{ Poor } \\
\hline & Validation & & 0.948 & 0.127 & & \\
\hline \multirow{2}{*}{$\mathrm{C} 51$} & Training & \multirow{2}{*}{ PCR } & 0.984 & 0.238 & \multirow{2}{*}{2.173} & \multirow{2}{*}{ Poor } \\
\hline & Validation & & 0.924 & 0.517 & & \\
\hline \multirow{2}{*}{ C52 } & Training & \multirow{2}{*}{ Least square } & 0.997 & 0.058 & 6863 & Poor \\
\hline & Validation & & $\mathbf{0 . 8 7 3}$ & 0.396 & $0.00 \mathrm{~s}$ & 1001 \\
\hline C61 & Training & I eact square & 0.999 & 0.011 & 4102 & Poor \\
\hline $\cos$ & Validation & Least square & 0.977 & 0.045 & 4.192 & Poor \\
\hline C62 & Training & Least sauare & 0.997 & 0.039 & 5980 & Poor \\
\hline$c 02$ & Validation & Least square & 0.335 & 0.235 & 0.980 & Poor \\
\hline
\end{tabular}

Besides, a graphical comparison was carried out by plotting the observed, predicted pore pressure values, lower limit (LL 5\%), and upper limit (UL 5\%) and presented in Figure 2. This figure confirms that the best HST models predict well the daily pore water pressure in embankment dam Heimer (C11, C22, C31, and C41), as the predicted values are inside into the $95 \%$ confidence interval of the baseline models. However, except for the cell C52 and C51, it was observed that the HST has fairly reproduced the pore water pressure during the periods from January 01, 2020, to Mars 01, 2020, for C21 and C32, from January 01, 2020, to July 01, 2020, for C42, from Jan 01, 2020, to June 25, 2020, for C62, and from January 01, 2020, to 08 May 01, 2020, for C61. Similarly, for the piezometer C31, the HST model is deteriorating during December 2020. The RMSE values for these periods were calculated and found to be $0.081,0.145,0.086,0.041$, and $0.012 \mathrm{~m}$ for predicting pore water pressure for

343 C21, C32, C42, C62, and C61 Piezometers, respectively. Basing on this analysis, it can be 344 concluded that the HST models can be deteriorated over time, as they presented good 345 prediction accuracy during the first semesters of the 2020 year. 

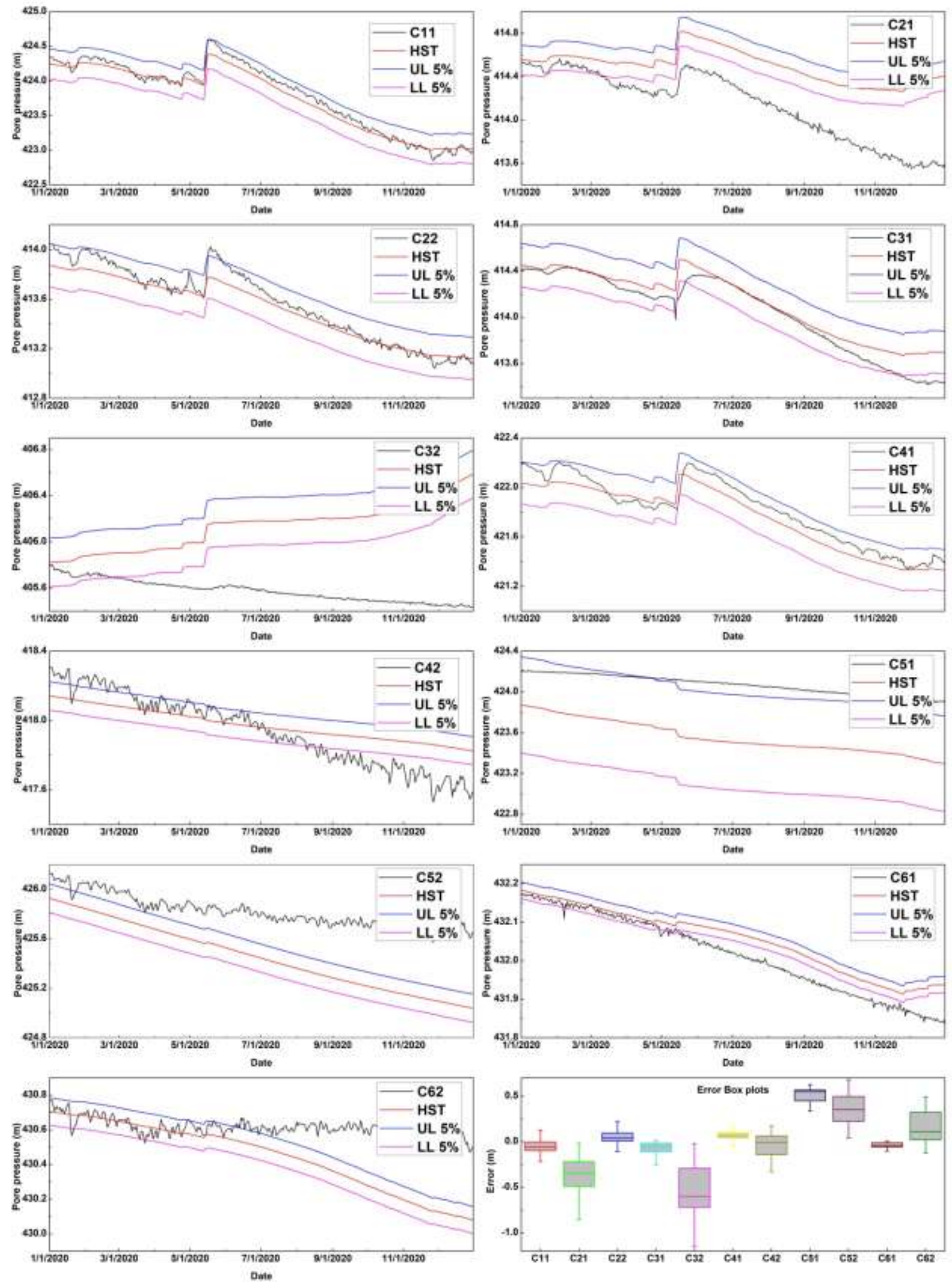

Figure 2: Graphical evaluation of the HST models during the validation phase. 
As shown in the bottom right of Figure 2, Box plots show that the HST model errors are normally distributed over small values in predicting C11, C22, C31, C41, C42, and C61 VW

350

351

352

353

354

355

356

357

358

359

360

361

362

363

364

365

366

367

368

369

370

371

372

373

374

375

376

377

378

379

380

381 Piezometers during the year 2020. Although the HST model had Poor GA as presented in Table 3 and reproduced values outside of 95\% confidence interval (CI) Figure 2, it has perfect error distributions in simulating C42 and C61. This may be due to the over-fitting problem, which has produced narrows CI and, therefore, it is likely the predicted values are outside of the CI.

To further investigate this approach in predicting the daily pore pressure, we adjusted new HST models keeping the same formats and including the dataset of the previous periods in the training phases to evaluate again the periods where these models will have deteriorated in the simulation. Table 4 presents the RMSEs of the model adjusted and the simulation periods used. This Table confirmed that the GA of the HST models has deteriorated over time in predicting the pore water pressure for C21, C32, C42, C61, and C62 Piezometers. However, continuous adjusting of these models shows being an alternative to improve the prediction accuracy. These results demonstrate some utility of the HST models in predicting the pore water pressure for the previous Piezometers and can be considered useful in short periods. Basing on the results presented in Table 4, it can be concluded that the HST models require a continuous adjustment to improve the accuracy in predicting the daily pore water pressure, as it was observed that not all models have presented good prediction accuracy for the whole of the 2020 year.

Table 4: Model performances for short periods in 2020

\begin{tabular}{|c|c|c|c|c|c|c|c|c|c|}
\hline \multicolumn{2}{|l|}{$\mathrm{C} 21$} & \multicolumn{2}{|l|}{$\mathrm{C} 32$} & \multicolumn{2}{|l|}{$\mathrm{C} 42$} & \multicolumn{2}{|l|}{ C61 } & \multicolumn{2}{|l|}{ C62 } \\
\hline periods & RMSE & periods & RMSE & periods & RMSE & periods & RMSE & periods & RMSE \\
\hline Jan 1 to Mars & 0.081 & Jan 1 to Mars 1 & 0.145 & Jan 1 to Jul 1 & 0.086 & Jan 1 to Mai 08 & 0.012 & Jan 1 to Jun 25 & 0.041 \\
\hline Mars 2 to Jun 1 & 0.132 & Mars 2 to Mai 15 & 0.111 & Jul 2 to Dec 31 & 0.090 & Mai 08 to Dec 31 & 0.025 & 26 Jun to Dec 31 & 0.066 \\
\hline Jun 2 to Oct 9 & 0.094 & Mai 16 to Dec 31 & 0.140 & & & & & & \\
\hline Oct 10 to Dec 31 & 0.073 & & & & & & & & \\
\hline
\end{tabular}

The lower GA of the HST model in predicting the pore pressure (for the C21, C32, C42, C61, and C62 piezometers) may be due to the fact that the hydrostatic effects do not vary instantaneously with the pore water pressure, while they are delayed due to the low hydraulic conductivity of the dam. Besides, the HST variables are considered independent. Therefore, there is a need to investigate other statistical approaches such as machine learning-based models with exogenous inputs that could be valuable to overcome this limitation of the HST model.

\subsection{ML development}

\subsubsection{Tuning of the ML models}

To avoid the over-fitting or under-training problems in machine learning development, the tuning and cross-validation $(\mathrm{CV}=2,5,10$, and 20) processes are crucial steps in selecting the best models (Arlot and Celisse, 2010). Besides, selecting the more informative input features 
and deleting the redundant ones are required to improve the generalization ability (Kuhn and Johnson, 2019). The hyper-parameter, functions, and the input variables are selected based on trial error procedures. Table 5 illustrates the hyper-parameters and functions selected and adopted in this study.

Table 5: Selected input variables, Hyper-parameter, and functions of the trained models

\begin{tabular}{|c|c|}
\hline Selected input variables & $\mathrm{y}_{\mathrm{i}-1}, \mathrm{y}_{\mathrm{i}-2}, \mathrm{x}_{\mathrm{i}}, \mathrm{x}_{\mathrm{i}-1}$, and $\mathrm{x}_{\mathrm{i}-2}$ \\
\hline Model & Parameters/ functions/algorithm \\
\hline \multirow{8}{*}{ ANN } & 3 layers \\
\hline & 12 neurons in hidden layer \\
\hline & Algorithm: Adam \\
\hline & Function activation: Sigmoid \\
\hline & Identity in output layer \\
\hline & Epoch number: 1000 \\
\hline & Learning rate: 0.01 \\
\hline & Momentum coefficient: 0.85 \\
\hline \multirow{3}{*}{ SVR } & $\mathrm{C}=300$ \\
\hline & Kernel function: linear $(\gamma=1.2)$ \\
\hline & $\varepsilon$-function loss, $\varepsilon=0.002$ \\
\hline MLR & Algorithm: ridge \\
\hline \multirow{3}{*}{ AdaBoost } & loss function : Exponential \\
\hline & learning rate: 0.5 \\
\hline & Estimator number: 250 \\
\hline
\end{tabular}

\subsubsection{ML model Performances}

Table 6 presents some performances of machine learning models in predicting the pore water pressure during the training and validation processes such as coefficient of determination $\mathrm{R}^{2}$, root mean square error (RMSE), and generalization ability (GA). As shown in Table 6, it is observed that, except for the AdaBoost model, all other models have good accuracy in predicting the pore water pressure with lower RMSE values for validation datasets (ranging from 0.007 to $0.059 \mathrm{~m}$ ). According to the results during the validation phase, the AdaBoost model is considered unsuitable for pore water pressure prediction purposes, as it presented lower $\mathrm{R}^{2}$ values and has 'Poor" GA. Meanwhile, the GA of the other models generally varies from one model to another and from one piezometer to another. It was observed that, except for ANN (in C11, C22, C31, and C41 Piezometers), SVR (in C32 and C22 VW Piezometer), and MLR (in C11 and C31 Piezometers), the models have "Good"' to "'Excellent'" GA. These variations in model performances can be justified by the fact that different parts of the dams behave differently and, therefore, the complexity of the responses is too different. 
Table 6: ML performances during training and validation processes

\begin{tabular}{|c|c|c|c|c|c|c|c|}
\hline \multirow{2}{*}{ piezometer } & \multirow{2}{*}{ model } & $\mathrm{R}^{2}$ & $\operatorname{RMSE}(\mathrm{m})$ & $\mathrm{R}^{2}$ & $\operatorname{RMSE}(\mathrm{m})$ & \multirow{2}{*}{\multicolumn{2}{|c|}{ GA }} \\
\hline & & \multicolumn{2}{|c|}{ Training } & \multicolumn{2}{|c|}{ Validation } & & \\
\hline \multirow{4}{*}{$\mathrm{C} 11$} & SVR & 0.999 & 0.086 & 0.996 & 0.059 & 0.689 & Good \\
\hline & MLR & 0.999 & 0.087 & 0.995 & 0.035 & 0.401 & Poor \\
\hline & ANN & 0.999 & 0.103 & 0.994 & 0.050 & 0.481 & Poor \\
\hline & AdaBoost & 0.999 & 0.096 & 0.676 & 0.387 & 4.036 & Poor \\
\hline \multirow{4}{*}{$\mathrm{C} 21$} & SVR & 0.990 & 0.040 & 0.995 & 0.026 & 0.656 & Good \\
\hline & MLR & 0.990 & 0.027 & 0.996 & 0.020 & 0.75 & Excellent \\
\hline & ANN & 0.990 & 0.029 & 0.996 & 0.028 & 0.950 & Excellent \\
\hline & AdaBoost & 0.990 & 0.047 & 0.667 & 0.350 & 7.447 & Poor \\
\hline \multirow{4}{*}{$\mathrm{C} 22$} & SVR & 0.990 & 0.158 & 0.994 & 0.030 & 0.191 & Poor \\
\hline & MLR & 0.990 & 0.027 & 0.994 & 0.024 & 0.876 & Excellent \\
\hline & ANN & 0.700 & 5.190 & 0.992 & 0.028 & 0.005 & Poor \\
\hline & AdaBoost & 0.990 & 0.030 & 0.692 & 0.433 & 14.438 & Poor \\
\hline \multirow{4}{*}{ C31 } & SVR & 0.990 & 0.047 & 0.998 & 0.058 & 1.229 & Excellent \\
\hline & MLR & 0.990 & 0.008 & 0.997 & 0.018 & 2.248 & Poor \\
\hline & ANN & 0.990 & 0.010 & 0.997 & 0.051 & 5.057 & Poor \\
\hline & AdaBoost & 0.990 & 0.009 & 0.447 & 0.393 & 43.710 & Poor \\
\hline \multirow{4}{*}{ C32 } & SVR & 0.990 & 0.039 & 0.989 & 0.015 & 0.384 & Poor \\
\hline & MLR & 0.990 & 0.014 & 0.993 & 0.008 & 0.568 & Good \\
\hline & ANN & 0.990 & 0.015 & 0.987 & 0.014 & 0.930 & Excellent \\
\hline & AdaBoost & 0.990 & 0.016 & 0.489 & 0.150 & 9.375 & Poor \\
\hline \multirow{4}{*}{ C41 } & SVR & 0.990 & 0.049 & 0.994 & 0.030 & 0.603 & Good \\
\hline & MLR & 0.990 & 0.008 & 0.998 & 0.011 & 1.409 & Good \\
\hline & ANN & 0.990 & 0.013 & 0.996 & 0.030 & 2.315 & Poor \\
\hline & AdaBoost & 0.990 & 0.015 & 0.734 & 0.220 & 14.695 & Poor \\
\hline \multirow{4}{*}{$\mathrm{C} 42$} & SVR & 0.990 & 0.051 & 0.984 & 0.046 & 0.905 & Excellent \\
\hline & MLR & 0.990 & 0.019 & 0.985 & 0.026 & 1.371 & Good \\
\hline & ANN & 0.990 & 0.021 & 0.985 & 0.042 & 2.000 & Good \\
\hline & AdaBoost & 0.990 & 0.023 & 0.162 & 0.331 & 14.371 & Poor \\
\hline \multirow{4}{*}{ C51 } & SVR & 0.990 & 0.061 & 0.972 & 0.032 & 0.527 & Good \\
\hline & MLR & 0.990 & 0.004 & 0.994 & 0.007 & 1.747 & Good \\
\hline & ANN & 0.990 & 0.008 & 0.995 & 0.010 & 1.237 & Excellent \\
\hline & AdaBoost & 0.990 & 0.006 & 0.009 & 0.175 & 29.125 & Poor \\
\hline \multirow{4}{*}{ C52 } & SVR & 0.990 & 0.036 & 0.964 & 0.035 & 0.975 & Excellent \\
\hline & MLR & 0.990 & 0.022 & 0.965 & 0.023 & 1.067 & Excellent \\
\hline & ANN & 0.990 & 0.024 & 0.965 & 0.031 & 1.296 & Excellent \\
\hline & AdaBoost & 0.990 & 0.025 & 0.050 & 0.251 & 10.051 & Poor \\
\hline \multirow{4}{*}{ C61 } & SVR & 0.990 & 0.044 & 0.974 & 0.023 & 0.521 & Good \\
\hline & MLR & 0.990 & 0.007 & 0.996 & 0.007 & 0.932 & Excellent \\
\hline & ANN & 0.990 & 0.012 & 0.995 & 0.010 & 0.811 & Excellent \\
\hline & AdaBoost & 0.990 & 0.008 & 0.794 & 0.200 & 24.991 & Poor \\
\hline \multirow{4}{*}{ C62 } & SVR & 0.990 & 0.036 & 0.754 & 0.029 & 0.805 & Excellent \\
\hline & MLR & 0.990 & 0.025 & 0.793 & 0.024 & 0.940 & Excellent \\
\hline & ANN & 0.990 & 0.029 & 0.697 & 0.032 & 1.103 & Excellent \\
\hline & AdaBoost & 0.990 & 0.030 & 0.160 & 0.066 & 2.204 & Poor \\
\hline
\end{tabular}


However, the comparison of the ML model performances with the HST model showed obviously the superiority of the ML models except for the AdaBoost model. Besides, the ML models also showed being more generalizable than the HST model. Interestingly, comparing the MLR and HST model performances shows that the NARX method is suggested in selecting the input variables for modeling the daily pore water pressure in the embankment dam, as these models are based on a similar principle. Therefore, this method is valuable to overcome the HST limitations-related assumption.

An additional qualitative metric for evaluating the prediction models is the confidence interval (CI) with which the engineers can identify the anomalies during the interpretation of the measurements. However, Table 7 presents the CI of the selected models with $95 \%$ as confidence level. This Table shows that the CIs of the HST are wider than those of the SVR, MLR, and ANN models.

Table 7: Widths of CI (95\%) of the suitable models.

\begin{tabular}{ccccc}
\hline \hline \multirow{2}{*}{ Piezometer } & \multicolumn{3}{c}{ Models } & \\
\cline { 2 - 5 } & MLR & ANN & SVR & HST \\
\hline \hline C11 & $*$ & $*$ & 0.324 & 0.435 \\
\hline \hline C22 & 0.107 & 0.112 & 0.149 & 0.348 \\
\hline \hline C31 & 0.103 & $*$ & $*$ & 0.179 \\
\hline C32 & $*$ & $*$ & $*$ & $*$ \\
\hline \hline C41 & 0.054 & 0.058 & 0.187 & $* 341$ \\
\hline \hline C42 & 0.031 & $*$ & 0.179 & $*$ \\
\hline \hline C51 & 0.072 & 0.081 & 0.228 & $*$ \\
\hline \hline C61 & 0.017 & 0.031 & 0.126 & $*$ \\
\hline \hline C62 & 0.083 & 0.093 & 0.169 & $*$ \\
\hline \hline
\end{tabular}

423 Besides, Figure 3 illustrates the box plots of the ML model errors during the validation phase. AdaBoost model are larger than those that occurred by the ANN, SVR, and MLR models. These models have a perfect distribution of the errors over lower values, which indicate their stability during the simulation. By comparing the box plots of the errors with those of the HST models, it can be concluded that the based-machine learning models are superior and more accurate in predicting the pore water pressure. 

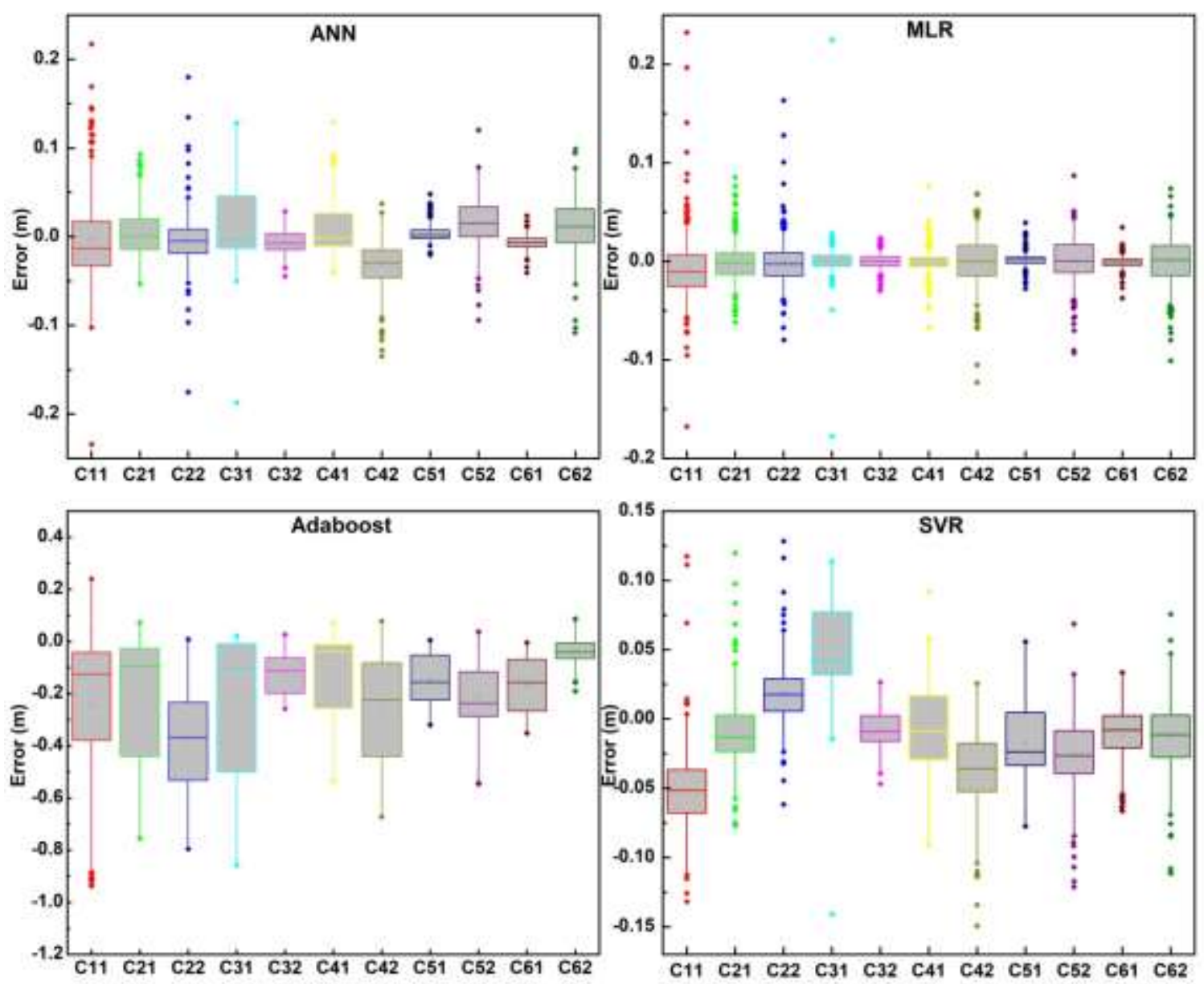

Figure 3: Box plot of the model errors for simulation of the pore water pressure during 2020.

\section{Discussion and practical implication}

Slope instability and internal erosion (due to the seepage) are considered among the most frequent causes of embankment dam failure in the world according to the ICOLD. Evaluating these indicators can be carried out by measurement and interpretation of the pore water pressure. According to the results of the study, the selected models presented in Table 7 are useful to analyze and interpret trends and variations of the pore water pressure under different loads, as they have high prediction accuracy and good to excellent GA. Results of our study are in agreement with previous studies in terms of prediction accuracy. For instance, De Granrut et al. (de Granrut et al., 2019) found that the ANN model is superior to HST model for predicting the piezometric levels in concrete dam. Kang et al. (Kang et al., 2017) compared ELM and traditional approaches for predicting concrete dam deformation model and showed the superiority of the ELM. Also, Ranković et al. (Ranković et al., 2014) confirmed the importance of the exogenous input variables during development of the ML models to overcome the lag time effects. Globally, ML models showed being more accurate approach and should be practically involved in dam behavior monitoring to enhance the safety. Nowadays, the studied dam is monitored in real-time through developed sensor technologies. Nevertheless, the interpretation and the behavior check-up of the dams are 
commonly carried out in interval in +-5 year intervals depending on the dam's importance in several countries including Morocco. Meanwhile, the dam responses to the small anomalies often are slow, particularly for embankment dams, which could be an initiation of a dam failure event. Therefore, evaluating early whether the variations of the measurements are normal or abnormal is a crucial task in dam safety monitoring.

Nowadays, artificial intelligence techniques, big data, and the internet of things (IoT) bottom up tools in monitoring processes for different fields. However, the practical implication of these approaches in dam safety monitoring needs accurate and generalizable models for interpreting measurement data with the aim to detect the anomalies. In this study, we studied the traditional statistical approach HST and machine learning-based models for predicting daily pore water pressure in embankment dam Heimer and the results showed the high potential of the prediction accuracy of the ML models. The implication of these models in the measurement interpretations and anomaly detections can be carried out by comparing the expected behaviors of the dam and the measured data. In other word, given that the baseline models have been developed based on the observed data during the normal periods, therefore, any abnormal dam behavior will lead to deterioration of the performances of these models, as the anomalies are generally due to the factors that are not considered while developing the baseline models. Interestingly, the confidence interval (CI) method is suggested for anomaly identification of the trend of the dam behaviors (Li et al., 2020). Indeed, the anomalies will lead to the measurements outside of the CI. Accordingly, if the CI is largely wide the abnormal values could not be detected. Meanwhile, if the CI is too narrow, the normal behaviors may be deemed anomalies mistakenly. For this purpose, the authors suggested using all best fitted-models rather than one model for prediction and interpretation purposes. Since the monitoring process of the studied dam is carried out in real-time, the implementation and integration of the selected models in a platform will allow the practice engineers to compare the predicted and observed trends of the pore water pressure with high frequency and, therefore, will enhance the dam safety by detecting the anomalies early. Although the developed method is capable to detect the anomalies related-trend variations of the pore water pressure, it is not able to identify type of the anomalies because the VW piezometer failure could lead to the anomalies. In such a case, coupling the prediction results and engineering expertise is required for decision-making. Specifically, analyzing the manual measurements with regard to the physical causality can identify the anomaly types (i.e. a high fluctuation in pore water pressure during short time implies the failure of the sensors as demonstrated by an example presented in appendix A). However, the coupling of classification-regression ML-models and development relationships between the pore water pressures at different piezometers could be valuable in identifying the type of the anomalies (Fisher et al., 2017; Jung et al., 2015).

\section{Conclusion and further research paths}

Accurate predicting the pore water pressure in embankment dams is a challenging problem in dam safety monitoring. The pore water pressure is a non-linear time-varying function of water reservoir level, irreversible factors, and other unexplained or unexpected factors. In this study, four ML models with the NARX input method are developed and compared with the 
traditional statistical approach (HST) in predicting the daily pore water pressure. The main findings of this study are as follow:

1. Generalization ability (GA) of the models is a crucial metric in addition to the prediction accuracy in evaluating models for practical implications.

2. SVR and MLR are accurate and generalizable models for predicting the pore water pressure for 9 piezometers followed by ANN for 6 piezometers, and HST for 4 piezometers on 11 piezometers.

3. Prediction accuracy of the HST model can be deteriorated over time.

4. In overall, ML models are more accurate and stable than HST.

To sum up, ML-based models with the NARX input method are powerful and useful tools for modeling the daily pore water pressure where they can overcome some limitations of the HST model, particularly instantaneous response assumption. However, this study focused on regression models for predicting the trends of the pore water pressure rather than detecting directly the anomalies. Meanwhile, the ML models for classification tasks could be valuable to classify the dam behaviors and anomalies, and, therefore, they are suggested in future work.

\section{Acknowledgment}

This work is supported by River Basin Agency of Bouregreg and Chaouia as manager of the Heimer dam by providing data required. Authors thank the agency for great assistance and help.

Funding sources: The authors have not received any funding for this research

Competing interest: There is no conflict of interest

Data availability: All data and materials used in this study are valuable en request

Ethical approval: Not applicable.

Consent to participate: Not applicable.

Consent to publish: Not applicable

Author's Contributions: Ali EL BILALI: Writing - original draft, conceptualization, methodology, visualization, Formal analysis. MOUKHLISS MOHMMED: review \& editing. TALEB ABDESLAM: Writing - review \& editing, supervision. AYOUB NAFII: Writing - review \& editing, formal analysis. BAHIJA ALABJAH: review \& editing, formal analysis. YOUSSEF BROUZIYNE: review \& editing, formal analysis. NOUHAILA 
522 MAZIGH: review \& editing, formal analysis. KHALID TEZNIN: review \& editing, formal analysis, project administration. MADARK MHAMMED: review \& editing, formal analysis.

Appendix A: Example of hourly measurements provided by a failed VW piezometer.

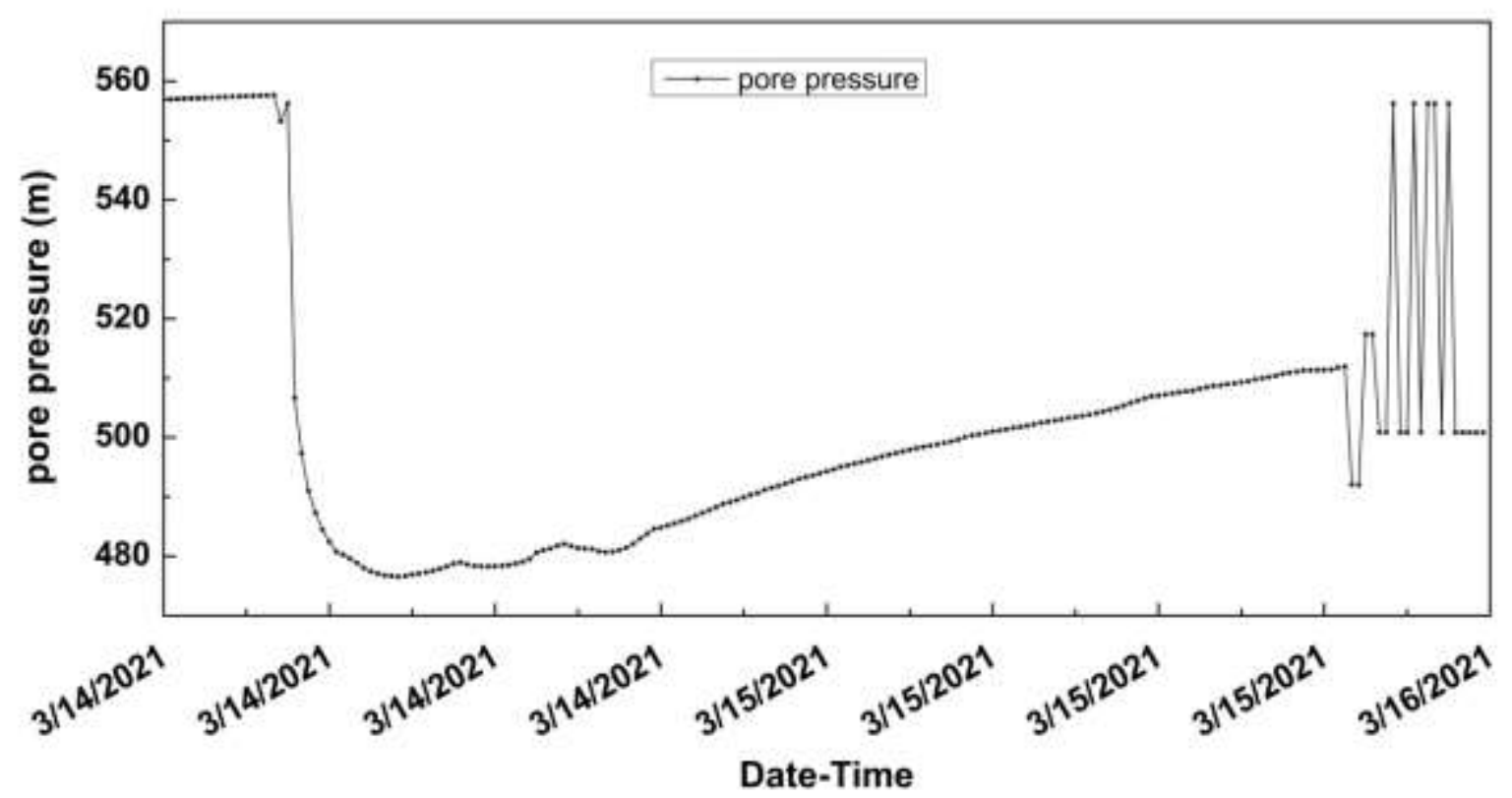

532

533

534

535

536

537 


\section{References}

547

548

549

550

551

552

553

554

555

556

557

Aggarwal, C.C., 2015. Data Mining, Springer International Publishing. https://doi.org/10.1007/978-3-319-14142-8

Al-Fares, W., 2011. Contribution of the geophysical methods in characterizing the water leakage in Afamia B dam, Syria. J. Appl. Geophys. 75, 464-471. https://doi.org/10.1016/j.jappgeo.2011.07.014

Al-Saigh, N.H., Mohammed, Z.S., Dahham, M.S., 1994. Detection of water leakage from dams by self-potential method. Eng. Geol. 37, 115-121. https://doi.org/10.1016/00137952(94)90046-9

Arlot, S., Celisse, A., 2010. A survey of cross-validation procedures for model selection. Stat. Surv. 4, 40-79.

Bear, J., 2013. Dynamics of fluids in porous media. Courier Corporation.

Belmokre, A., Mihoubi, M.K., Santillan, D., 2019. Seepage and dam deformation analyses with statistical models: Support vector regression machine and random forest. Procedia Struct. Integr. 17, 698-703. https://doi.org/10.1016/j.prostr.2019.08.093

Beskhyroun, S., Wegner, L.D., Sparling, B.F., 2011. Monitoring of long-term static deformation data of Fei-Tsui arch dam using artificial neural network-based approaches. 
Bishop, C.M., 2006. Pattern recognition and machine learning. springer.

565

566

567

568

569

570

571

572

573

574

575

576

577

578

579

580

581

582

Bonaccorso, G., 2018. Machine Learning Algorithms: Popular algorithms for data science and machine learning. Packt Publishing Ltd.

Bonelli, S., Félix, H., 2001. Delayed response analysis of temperature effect. 6th ICOLD Benchmark Work. Numer. Anal. Dams , 2001 1-9.

Carrere, A., Noret-Duchêne, C., 2001. Interpretation of an arch dam behaviour using enhanced statistical models, in: Proceedings of the Sixth ICOLD Benchmark Workshop on Numerical Analysis of Dams, Salzburg, Austria.

Chen, C., He, W., Zhou, H., Xue, Y., Zhu, M., 2020. A comparative study among machine learning and numerical models for simulating groundwater dynamics in the Heihe River Basin, northwestern China. Sci. Rep. 10, 1-13. https://doi.org/10.1038/s41598-02060698-9

Chen, S., Gu, C., Lin, C., Hariri-Ardebili, M.A., 2021. Prediction of arch dam deformation via correlated multi-target stacking. Appl. Math. Model. 91, 1175-1193. https://doi.org/10.1016/j.apm.2020.10.028

Chen, S., Gu, C., Lin, C., Wang, Y., Hariri-Ardebili, M.A., 2020. Prediction, monitoring, and interpretation of dam leakage flow via adaptative kernel extreme learning machine. Meas. J. Int. Meas. Confed. 166, 108161. https://doi.org/10.1016/j.measurement.2020.108161

Chouinard, L., Roy, V., 2006. Performance of Statistical Models for Dam. Jt. Int. Conf. Comput. Decis. Mak. Civ. Build. Eng. 2211, 199-207. 
Dawson, C.W., Wilby, R., 1998. Une approche de la modélisation pluie-deblt par ies réseaux neuronaux artificiels. Hydrol. Sci. J. 43, 47-66. https://doi.org/10.1080/02626669809492102

de Granrut, M., Simon, A., Dias, D., 2019. Artificial neural networks for the interpretation of piezometric levels at the rock-concrete interface of arch dams. Eng. Struct. 178, 616634. https://doi.org/10.1016/j.engstruct.2018.10.033

Desideri, A., Fontanella, E., Pagano, L., 2013. Pore water pressure distribution for use in stability analyses of earth dams. Landslide Sci. Pract. Risk Assessment, Manag. Mitig. 6, 149-153. https://doi.org/10.1007/978-3-642-31319-6_21

El Bilali, A., Taleb, A., Boutahri, I., 2021. Application of HEC-RAS and HEC-LifeSim models for flood risk assessment. J. Appl. Water Eng. Res. 9, 1-16. https://doi.org/10.1080/23249676.2021.1908183

El Bilali, A., Taleb, A., Brouziyne, Y., 2020. Groundwater quality forecasting using machine learning algorithms for irrigation purposes. Agric. Water Manag. 106625. https://doi.org/10.1016/j.agwat.2020.106625

Ferry, S., Willm, G., 1958. Méthodes d'analyse et de surveillance des déplacements observés par le moyen de pendules dans les barrages, in: VIth International Congress on Large Dams. pp. 1179-1201.

Fisher, W.D., Camp, T.K., Krzhizhanovskaya, V. V., 2017. Anomaly detection in earth dam and levee passive seismic data using support vector machines and automatic feature selection. J. Comput. Sci. 20, 143-153. https://doi.org/10.1016/j.jocs.2016.11.016

Freund, Y., Schapire, R.E., 1997. A Decision-Theoretic Generalization of On-Line Learning and an Application to Boosting. J. Comput. Syst. Sci. 55, 119-139. 
Freund, Y., Schapire, R.E., 1996. Experiments with a new boosting algorithm, in: Icml. Citeseer, pp. 148-156.

Gamse, S., Zhou, W.H., Tan, F., Yuen, K.V., Oberguggenberger, M., 2018. Hydrostaticseason-time model updating using Bayesian model class selection. Reliab. Eng. Syst. Saf. 169, 40-50. https://doi.org/10.1016/j.ress.2017.07.018

Ghosh, S., 2010. SVM-PGSL coupled approach for statistical downscaling to predict rainfall from GCM output. J. Geophys. Res. Atmos. 115, 1-18. https://doi.org/10.1029/2009JD013548

Guo, X., Baroth, J., Dias, D., Simon, A., 2018. An analytical model for the monitoring of pore water pressure inside embankment dams. Eng. Struct. 160, 356-365. https://doi.org/10.1016/j.engstruct.2018.01.054

Hariri-Ardebili, M.A., Pourkamali-Anaraki, F., 2018. Simplified reliability analysis of multi hazard risk in gravity dams via machine learning techniques. Arch. Civ. Mech. Eng. 18, 592-610. https://doi.org/10.1016/j.acme.2017.09.003

Hastie, T., Tibshirani, R., Friedman, J., 2009. The elements of statistical learning: data mining, inference, and prediction. Springer Science \& Business Media.

Johansson, S., 1997. Seepage monitoring in embankment dams.

Jung, I.S., Berges, M., Garrett, J.H., Poczos, B., 2015. Exploration and evaluation of AR, MPCA and KL anomaly detection techniques to embankment dam piezometer data. Adv. Eng. Informatics 29, 902-917. https://doi.org/10.1016/j.aei.2015.10.002

Kang, F., Li, J., Dai, J., 2019. Prediction of long-term temperature effect in structural health 
monitoring of concrete dams using support vector machines with Jaya optimizer and salp swarm algorithms. Adv. Eng. Softw. 131, 60-76. https://doi.org/10.1016/j.advengsoft.2019.03.003

Kang, F., Liu, J., Li, J., Li, S., 2017. Concrete dam deformation prediction model for health monitoring based on extreme learning machine. Struct. Control Heal. Monit. 24, 1-11. https://doi.org/10.1002/stc.1997

Kubat, M., 2017. An Introduction to Machine Learning, Springer International Publishing. https://doi.org/10.1007/978-3-319-63913-0

Kuhn, M., Johnson, K., 2019. Feature engineering and selection: A practical approach for predictive models. CRC Press. https://doi.org/10.1201/9781315108230

Li, B., Yang, J., Hu, D., 2020. Dam monitoring data analysis methods: A literature review. Struct. Control Heal. Monit. 27, 1-14. https://doi.org/10.1002/stc.2501

Li, F., Wang, Z., Liu, G., Fu, C., Wang, J., 2015. Hydrostatic seasonal state model for monitoring data analysis of concrete dams. Struct. Infrastruct. Eng. 11, 1616-1631. https://doi.org/10.1080/15732479.2014.983528

Mata, J., 2011. Interpretation of concrete dam behaviour with artificial neural network and multiple linear regression models. Eng. Struct. 33, 903-910. https://doi.org/10.1016/j.engstruct.2010.12.011

Pagano, L., Fontanella, E., Sica, S., Desideri, A., 2010. Pore water pressure measurements in the interpretation of the hydraulic behaviour of two earth dams. Soils Found. 50, 295307. https://doi.org/10.3208/sandf.50.295

Panthulu, T. V., Krishnaiah, C., Shirke, J.M., 2001. Detection of seepage paths in earth dams 

using self-potential and electrical resistivity methods. Eng. Geol. 59, 281-295. https://doi.org/10.1016/S0013-7952(00)00082-X

Qin, T., Wang, H., Wang, G., Liu, Y., Li, X., 2017. Heterogeneous Influence on HydroThermal Behaviors Within the Core of an Embankment Dam. Geotech. Geol. Eng. 35, 2277-2290. https://doi.org/10.1007/s10706-017-0243-7

Ranković, V., Grujović, N., Divac, D., Milivojević, N., 2014. Development of support vector regression identification model for prediction of dam structural behaviour. Struct. Saf. 48, 33-39. https://doi.org/10.1016/j.strusafe.2014.02.004

Rehamnia, I., Benlaoukli, B., Jamei, M., Karbasi, M., Malik, A., 2021. Simulation of seepage flow through embankment dam by using a novel extended Kalman filter based neural network paradigm: Case study of Fontaine Gazelles Dam, Algeria. Meas. J. Int. Meas. Confed. 176. https://doi.org/10.1016/j.measurement.2021.109219

Rosipal, R., Trejo, L.J., 2001. Kernel Partial Least Squares Regression in Reproducing Kernel Hilbert Space. J. Mach. Learn. Res. 2, 97-123. https://doi.org/10.1162/15324430260185556

Salazar, F., Morán, R., Toledo, M., Oñate, E., 2017. Data-Based Models for the Prediction of Dam Behaviour: A Review and Some Methodological Considerations. Arch. Comput. Methods Eng. 24, 1-39. https://doi.org/10.1007/s11831-015-9157-9

Salazar, F., Toledo, M.A., Oñate, E., Morán, R., 2015. An empirical comparison of machine learning techniques for dam behaviour modelling. Struct. Saf. 56, 9-17. https://doi.org/10.1016/j.strusafe.2015.05.001

Schapire, R.E., 1999. A brief introduction to boosting. IJCAI Int. Jt. Conf. Artif. Intell. 2, $1401-1406$. 
SFOE, 2015. DamBASE user manual: Dam Behaviour Analysis Software Environment.

Sica, S., Pagano, L., Rotili, F., 2019. Rapid drawdown on earth dam stability after a strong earthquake. Comput. Geotech. 116, 103187. https://doi.org/10.1016/j.compgeo.2019.103187

Simon, A., Royer, M., Mauris, F., Fabre, J., 2013. Analysis and interpretation of dam measurements using artificial neural networks, in: Proceedings of the 9th ICOLD European Club Symposium, Venice, Italy.

Talukdar, P., Dey, A., 2019. Hydraulic failures of earthen dams and embankments. Innov. Infrastruct. Solut. 4. https://doi.org/10.1007/s41062-019-0229-9

Tang, D., Gordan, B., Koopialipoor, M., Armaghani, D.J., Tarinejad, R., Pham, B.T., Huynh, V. Van, 2020. Seepage analysis in short embankments using developing a metaheuristic method based on governing equations. Appl. Sci. 10, 1-23. https://doi.org/10.3390/app10051761

Vapnik, V.N., 1995. The nature of statistical learning. Theory.

Wang, S. wei, Xu, Y. li, Gu, C. shi, Bao, T. fei, 2018. Monitoring models for base flow effect and daily variation of dam seepage elements considering time lag effect. Water Sci. Eng. 11, 344-354. https://doi.org/10.1016/j.wse.2018.12.004

Willm, G., Beaujoint, N., 1967. Les méthodes de surveillance des barrages au service de la production hydraulique d'Electricité de France, problèmes anciens et solutions nouvelles, in: IXth International Congress on Large Dams. pp. 529-550.

Xiang, Y., Fu, S. yan, Zhu, K., Yuan, H., Fang, Z. yuan, 2017. Seepage safety monitoring model for an earth rock dam under influence of high-impact typhoons based on particle 

swarm optimization algorithm. Water Sci. Eng. 10, 70-77. https://doi.org/10.1016/j.wse.2017.03.005

699 Xu, C., Deng, C., 2011. Solving multicollinearity in dam regression model using TSVD. GeoSpatial Inf. Sci. 14, 230-234. https://doi.org/10.1007/s11806-011-0527-7

701 Yoon, H., Jun, S.C., Hyun, Y., Bae, G.O., Lee, K.K., 2011. A comparative study of artificial neural networks and support vector machines for predicting groundwater levels in a coastal aquifer. J. Hydrol. 396, 128-138. https://doi.org/10.1016/j.jhydrol.2010.11.002

Zewdu, A., 2020. Modeling the slope of embankment dam during static and dynamic stability analysis: a case study of Koga dam, Ethiopia. Model. Earth Syst. Environ. 6, 1963-1979. https://doi.org/10.1007/s40808-020-00832-8 